\title{
METHODOLOGY FOR THE ASSESSMENT OF THE DAMAGE COST RESULTING FROM A LARGE EARTHQUAKE IN THE VICINITY OF WELLINGTON
}

\author{
G. R. Birss*
}

1.

\author{
INTRODUCTION
}

At the request of the Earthquake and War Damage Commission, the New Zealand National Society for Earthquake Engineering set up a study group to determine the maximum probable loss the Commission may suffer by way of claims resulting from a large earthquake with its epicentre near Wellington.

The study group's task was to determine the order of cost of physical damage to buildings and their contents which could credibly be expected to result from large earthquake attack.

Seismic loss information for New Zealand conditions is minimal and it was therefore necessary to critically review published overseas data. Where appropriate, adjustments were made to accommodate New zealand conditions.

Loss information was compiled as the ratio of damage cost to building value and varied with felt earthquake intensity as well as with type of building construction.

The total value and structural classification of the building stock in the affected area was compiled and entered on a computer. A program was set up to enable loss calculations to be carried out for the appropriate building classification and for the relevant earthquake intensities. From this the total loss was calculated.

The results of the study expressed as monetary loss are confidential to the Earthquake and War Damage Commission. In this paper, therefore, results are not presented in absolute dollar terms, but are given as relative values.

2.

\section{PREVIOUS STUDIES}

In 1981 Darwin (1) estimated the total building and dwelling loss as a result of two envisaged earthquakes in Wellington with intensities MM VIII and $\mathrm{X}$. Buildings were divided into pre- and

* Ministry of Works and Development, Wellington. post-1968 categories. Two areas containing half the commercial floor area in wellington city were examined and the balance of building floor area for the two building classes in both Wellington city and surrounding affected communities assessed on a pro-rata basis. Darwin assessed damage versus Mercalli intensity relationships for the two building types as well as for dwellings. To take into account the loss of "fittings and facilities", the original loss calculation was doubled. The value of dwelling loss was about half the loss of commercial buildings in both events.

Dowrick (2) carried out an estimate of loss to properties insured with the New Zealand South British Insurance Group as a result of two earthquakes in turn, giving rise to modified Mercalli intensity values of $I X$ and $X$ in Wellington city. The latter event was predicted to result in 2.6 times the damage cost occurring due to the former event.

The computational procedure used by the study group followed that used by Dowrick in his study with some refinement.

3. DAMAGE ASSESSMENT METHOD

3.1 Selection of Earthquakes

Both the potential monetary losses from a large disaster and the average annual loss from all earthquakes over long periods of time are of concern to insurance interests. However, this study concentrated only on the former problem.

It was decided to look at earthquake events which would result in modified Mercalli intensities of IX and $X$ in Wellington city. A recent seismicity model for New Zealand (3), incorporating both geological and seismological information suggests that seismic activity is diffuse and is not constrained by the location of known faults. Hence locations of scenario earthquakes used in this study were chosen so that Smith's (4) more weakiy attenuated type $B$ earthquake would apply, thereby maximising the area of damaging effects. Two earthquakes for each value of MM intensity in Wellington were chosen, a total of four events.

BULLETIN OF THE NEW ZEALAND NATIONAL SOCIETY FOR EARTHQUAKE ENGINEERING, Vol 18, No 3, September 1985 


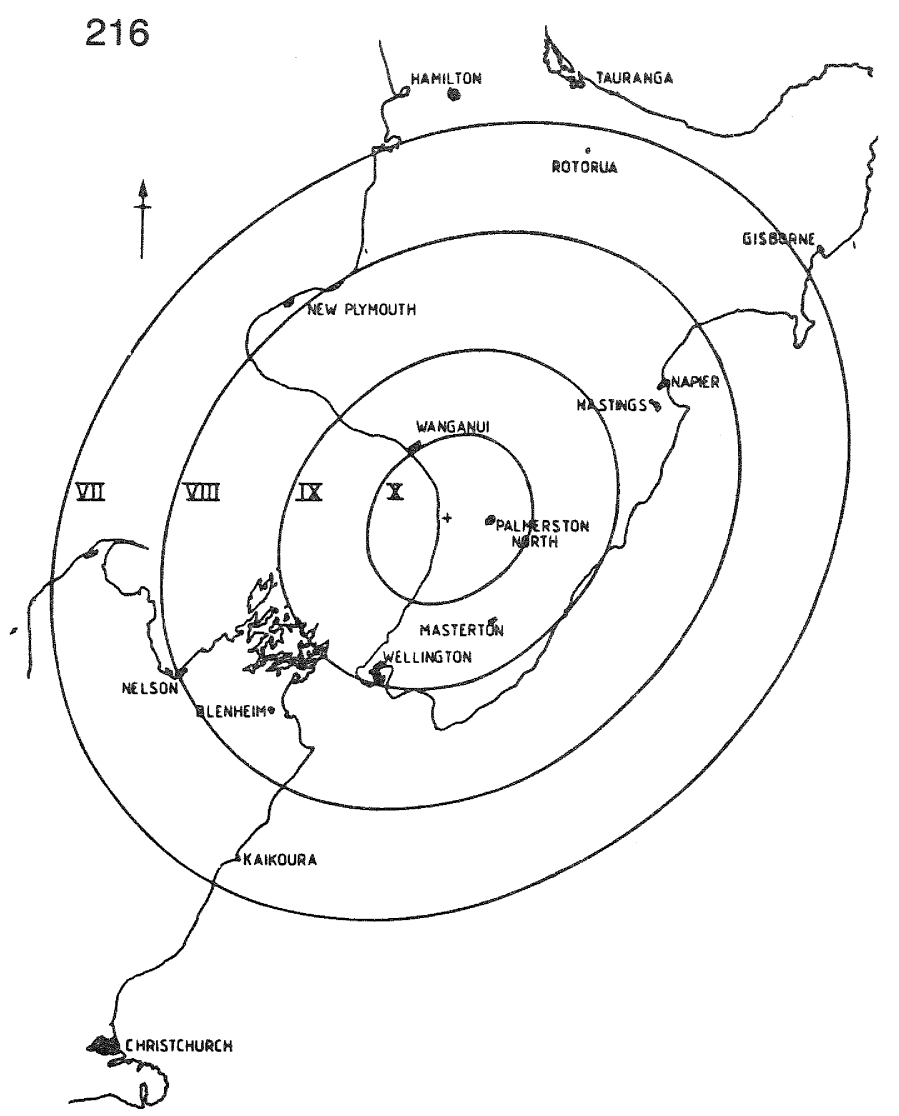

EVENT 1-MMIX IN WELLINGTON

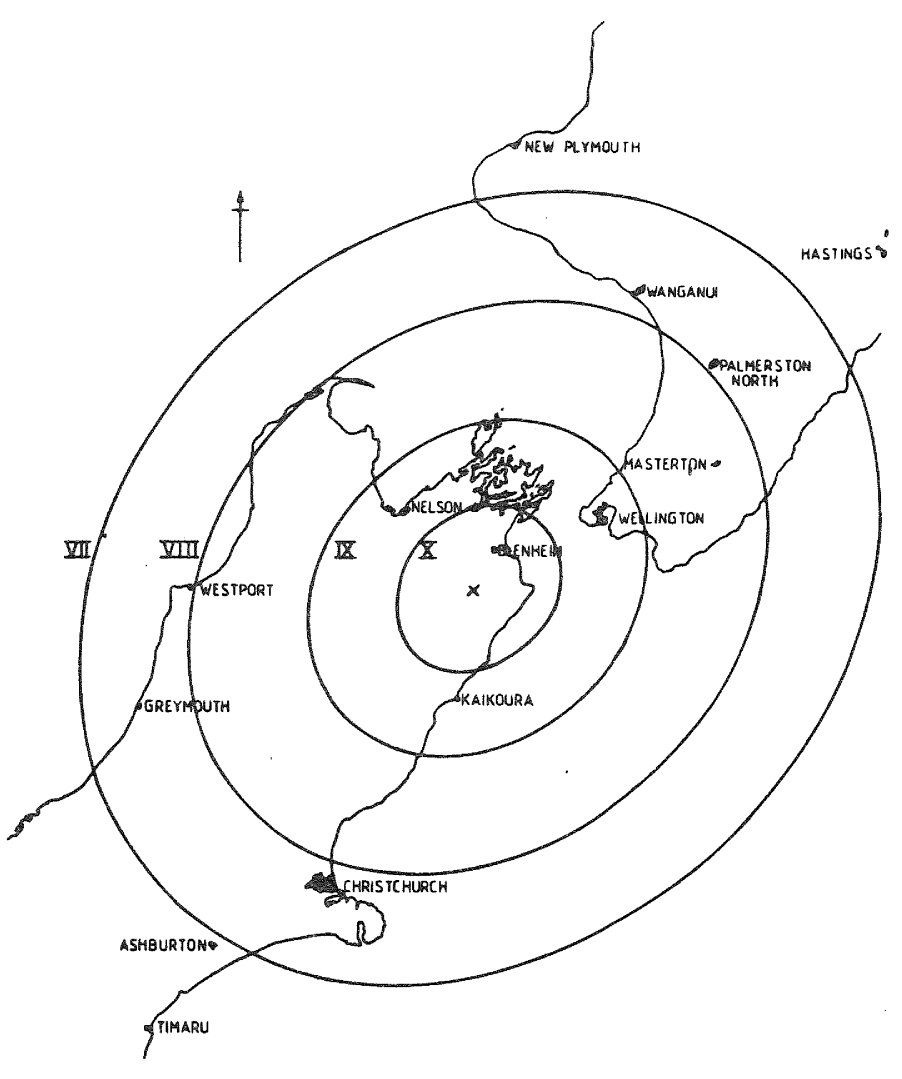

EVENT 2-MMIX IN WELLINGTON

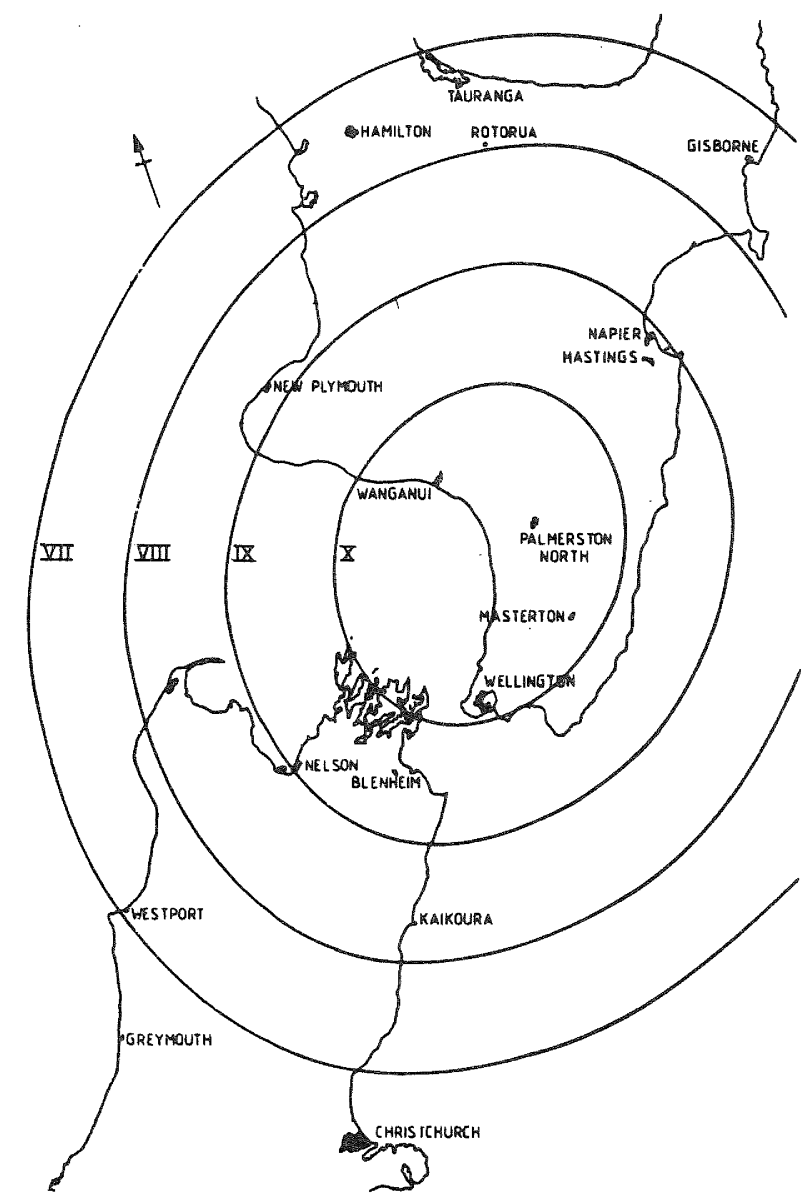

Fig. 1.

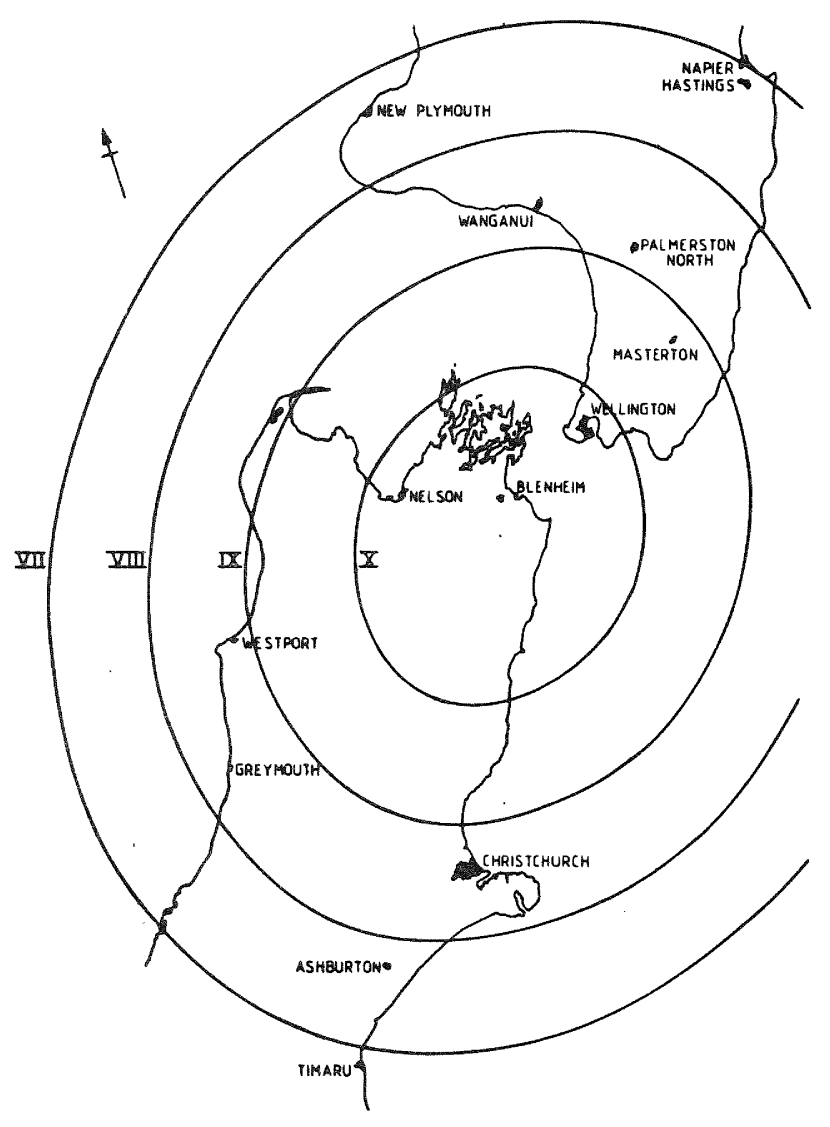

EVENT 4-MMX IN WELLINGTON

EVENT 3-MMX IN WELLINGTON

Earthquake Events Studied

$\stackrel{100}{1} \quad \begin{array}{ll}200 \\ \mathrm{kmm}\end{array}$ 
Areas as far to the north of Wellington and also as far to the south as possible were covered by appropriate positioning of the epicentres using the isoseismal formulae determined by Smith. (4). The four events are described in Figure 1 with the isoseismals plotted from smith's formulae.

The values of Richter magnitude for the scenario events were calculated in the same way as explained by Dowrick (2) to obtain most likely values. The frequency distributions with the number of events per annum versus Richter magnitude are shown in Figures 3 and 4 . As can be seen, the values of Richter magnitude occurring most frequently are 7.8 for the MM IX event, and 8.4 for the MM $X$ event. The average return periods for the event can be computed from Figures 3 and 4: MM IX 246 years; MM X 1100 years. The former value compares well with 220 years calculated more precisely by smith and Berryman (3) using the same seismicity model.

\section{$3.2 \quad$ Seismicity}

Large variations in the nature and intensity of ground shaking during an earthquake can occur within quite short distances. The method of delineating the soil types to correlate the sharp variations in shaking and damage is known as microzoning.

Smith's (4) formulae for calculating the spread of earthquake shaking effects from the earthquake source assumes average ground conditions. In the study variations due to ground conditions were applied only to buildings in the densely built Wellington metropolitan area.

Microzone areas have been delineated (5) for Wellington and Berryman's recommendations (6) were used to obtain the increment of $M M$ intensity for particu lar ground conditions. This was added to the value selected for average ground. The MM increments used were:

\section{Ground Description}

MM Increment

\section{Basement rock}

Compact sediment (assumed

average ground)

High porosity sediment

Deep alluvium

Hence, for Wellington city, the "average ground" intensity (MM) values were decreased by one unit for "basement rock" conditions and increased by one unit where "high porosity sediments" underlaid the buildings. All buildings in Lower Hutt were assumed to be founded on soft soil (deep alluvium) and the "average soil" MM value incremented by 2 ; an increment of 1.5 was applied to buildings in Petone (6), where ground conditions were considered to fall between the last two categories.

This refinement was not considered justified for buildings outside of the
Wellington metropolitan area or for houses in any area, as the total value of building concentrations experiencing severe shaking would be much less by comparison and because knowledge of soil conditions was less readily available.

\subsection{Classification and Valuation of Buildings}

In principle, the finer the subdivision of building classes, the less the error in estimate of damage for each class. However, because of the large numbers of buildings involved in the study and in order to take the greatest advantage from published data, a reasonably crude classification system was used.

Based on Valuation Department data buildings were grouped by the following classes:
a) houses (assuming timber-framed)
b) unreinforced masonry
c) pre-1936 reinforced concrete
d) 1936-1977 reinforced concrete
e) post-1977 reinforced concrete

The building classes were determined from the following considerations. The year 1936 was taken as the final year during which buildings not designed for earthquake resistance were completed. The lateral design level for buildings designed in accordance with the appropriate building code was basically unchanged from 1936-1977. The final year for which buildings not designed to the current Loadings Code (NZS 4203:1976) were occupied was assumed to be 1977 .

Under the 1944 Earthquake and War Damage Act, all property insured against loss or damage by fire becomes automatically insured for earthquake damage, up to the level of the property's indemnity value (7). There is unfortunately no single simple formula for establishing indemnity value. The quantity has been described as "replacement value minus depreciation", but neither of these quantities is readily available. However the study group were advised that the valuation Department's "equalised value", that is, current valuation for the covered property would be a satisfactory approximation to "indemnity value". For the purpose of this study, it was therefore decided to use Valuation Department statistics and computerised data "equalised" to March 1983. These valuations were taken to represent the maximum liability of the Earthquake and War Damage Commission.

3.4 Relationships Between Intensity and Building Damage

\subsubsection{Seismic Intensity and Damage}

In the modified Mercalli scale, levels of seismic intensity are defined by direct reference to effects on buildings. Summarising the effects of the San Fernando earthquake of 1971, Whitman (8) notes the following trends among the concrete and steel buildings: 


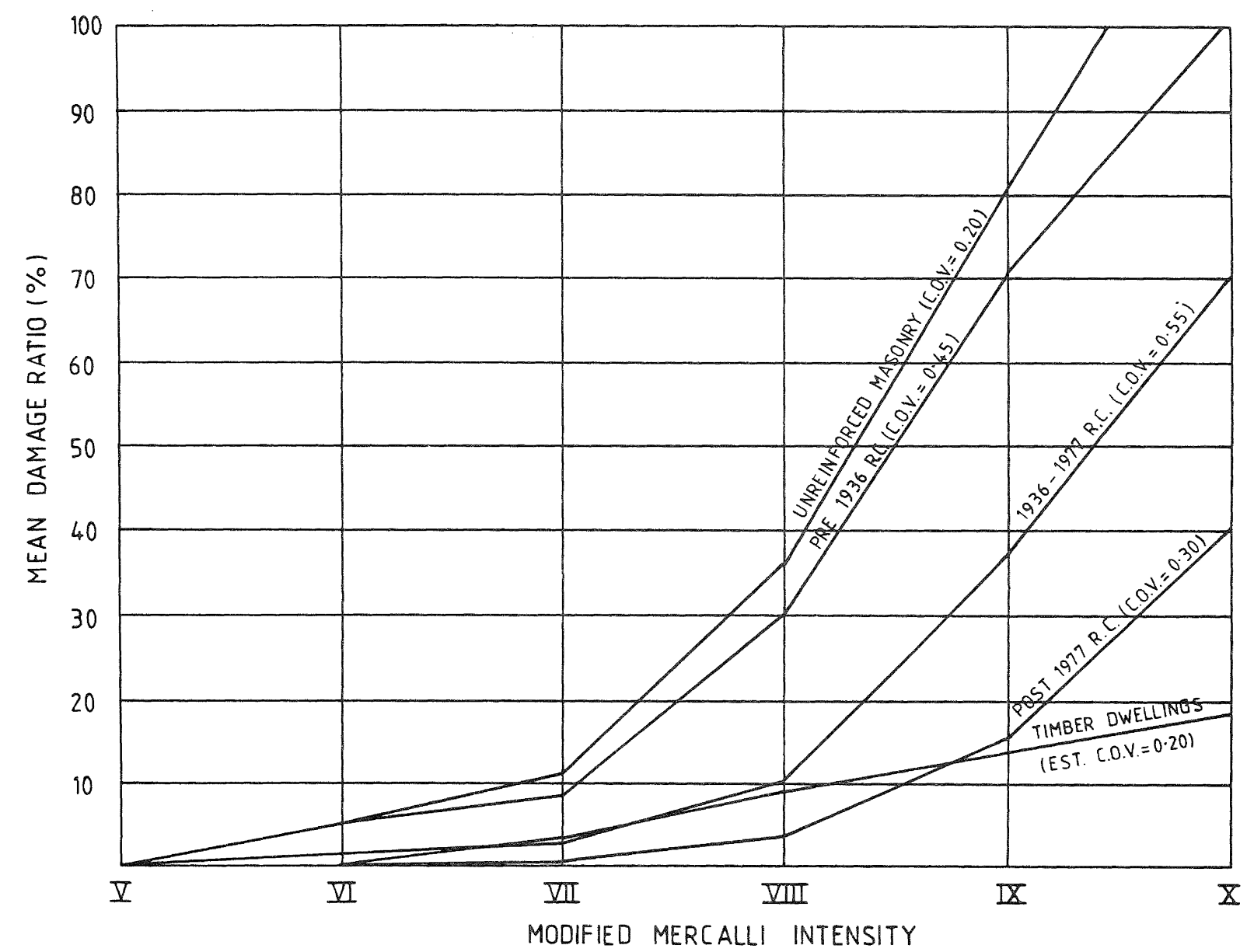

Fig. 2. Damage Intensity Relationships Used In This Study

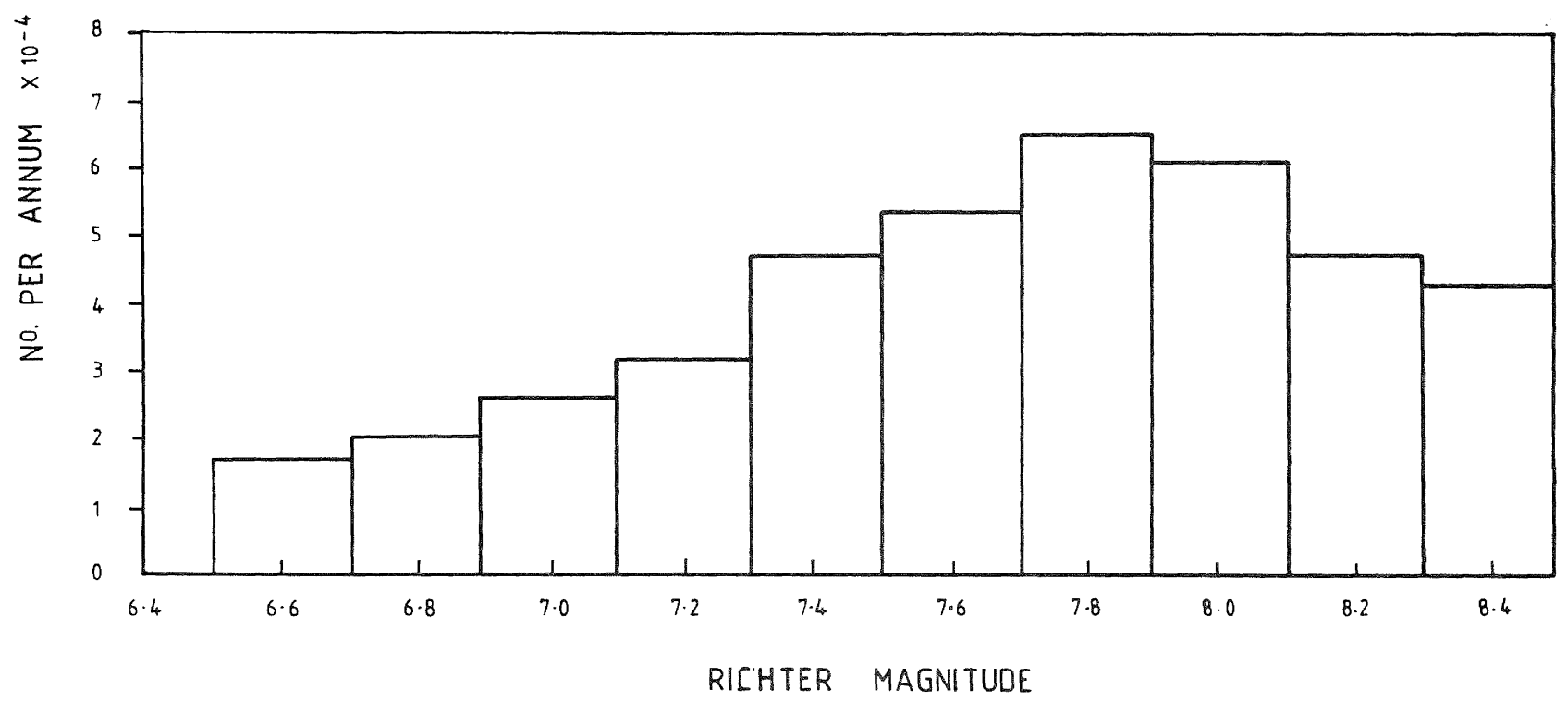

Fig. 3.

Frequency Distribution of Scenario Earthquakes

(a) MMIX Event 
MM VI Most buildings suffered no damage. Some buildings had partition wall cracks, but only to a very limited extent.

MM VII Significant damage to the pre1933 (pre-seismic design) buildings, while the performance of the modern buildings, both steel and concrete, was very satisfactory. Repair of cracks and partition walls accounted for most of the damage.

MM VII.5 Only the post-1947 (seismic design) steel buildings did not suffer extensive damage. The post-1947 concrete buildings were damaged considerably.

MM VIII Modern concrete buildings received very extensive structural damage.

\subsubsection{Mean Damage Ratios}

The "mean damage ratio" (MDR) expresses the value of damage to a building, resulting from earthquake shaking to a given value of modified Mercalli intensity (MM), as a proportion of the value of the building in its undamaged state. It is assumed that the value represented by the numerator is the cost of repairing the damage. The value described by the denominator is discussed subsequently.

The relationship between MDR and MM clearly depends on the nature of the building structure. As an example, unreinforced brickwork would be expected to experience far greater damage at a given value of MM than a modern reinforced concrete building.

The mean damage ratios for the different building classes given in section 3.4.1 are summarised in Figure 2 . They were derived from a variety of sources. Some published data was discounted on the basis that it was assessed for a situation where the standard of construction would probably be generally inferior to that applying in New Zealand.

Buildings of class (a) - housing - were assumed to be timber framed. MDR/ MM data for timber dwellings in the United States (9) was plotted together with a single estimate for New Zealand from Cooney and Fowkes (9). Based on the two points obtained for MM IX intensity, a constant value of coefficient of variation of 20 percent was assigned to the MDR/MM curve shown in Figure 2 .

For classes (b), (c) and (d) references (1) to (7) provided information but considerable scatter was evident in the data plotted from these references.

Building class (e) (post-1977) is typically the modern ductile building designed to deform and crack in a controlled, safe manner rather than fail in a brittle, possibly catastrophic way. There appears to be no published informa- tion on damage affecting this class of building. The MDR/MM relationship was obtained primarily by comparison with the curve already obtained for the 1936-1977 reinforced concrete buildings. The commentary on NZSS 1900:1965 chapter 8 (10) was referred to together with the component damage matrices of Whitman, Hong and Reed (11). It was decided to decrease the MDR value of 10 percent for class (d) (1936-1977) buildings at MM VIII to about 2.5 percent for class (e) buildings. Values at MM IX and $X$ were obtained by extrapolation for the new MM VIII value with the curve roughly parallel to the curve for the 1936-1977 buildings.

The bulk of information available for producing the MDR/MM curves was not "raw" but rather estimates derived from initial data. However Steinbrugge (12) asserts that "most loss data published in engineering and scientific reports after an earthquake require major interpretative efforts to have any use".

From the data obtained from various sources, the degree of scatter at each value of MM was quantified as the coefficient of variation (COV). The COV was often similar for different MM values within the same building class and by averaging, a constant value of COV was derived for the analysis of each class of structure (see Figure 2).

In their analysis of seismically designed buildings where MDR exceeded 10 percent, Whitman, Hong and Reed (11) report values of COV from 40 percent to 130 percent. Such high values of COV refiect the considerable uncertainty involved in a study such as this and this uncertainty should be noted.

There is a difference in MDR value depending on whether the denominator represents market value or replacement cost. The difference between the two values, arising from depreciation, inflation and market conditions, will obviously be greatest for old buildings. For the Los Angeles area, it was found (11) that market value generally exceeded replacement value for buildings less than about five years old, but then decreased to a constant 40 percent of replacement value.

If this is true in New Zealand, then it follows that values of MDR based on market value would be more than twice that based on replacement value for the majority of buildings considered in this study.

The various sources of data obtained during the study means that it was not always clear on what basis the MDRs were assessed. However, the final smoothed MDR/MM relationships were compared with MDR values reported by Whitman et al (11) for market value and for replacement cost and found to correlate best with those obtained on a market value basis.

The amount of money actually paid out for repair could exceed the product of MDR and market value by several-fold. 


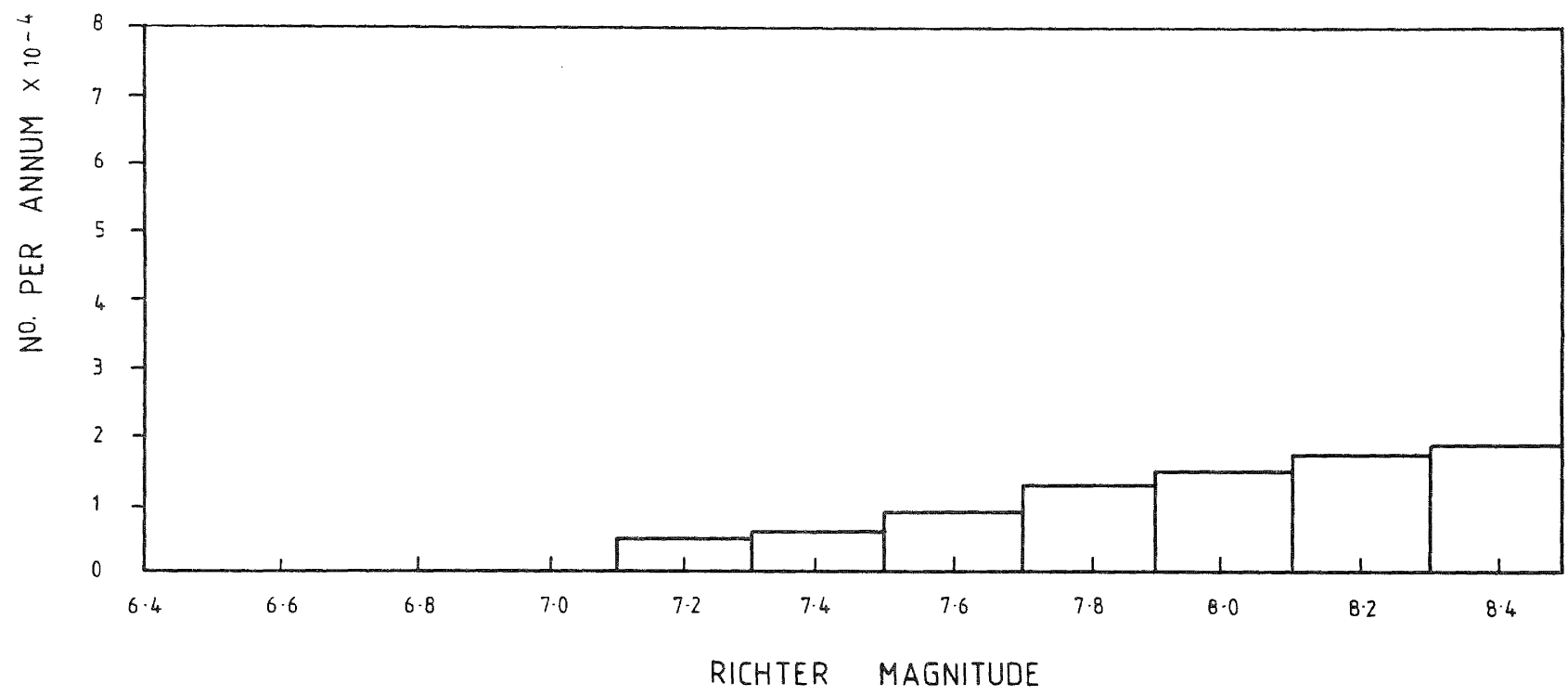

Fig. 4.

Frequency Distribution of Scenario Earthquakes

(b) MMX Event

\begin{tabular}{|lrrrrrrrrr|}
\hline Street & $\begin{array}{l}\text { Site } \\
\text { Cover }\end{array}$ & Area & $\begin{array}{l}\text { Capital } \\
\text { Value }\end{array}$ & $\begin{array}{l}\text { Land } \\
\text { Value }\end{array}$ & Use & Age & $\begin{array}{l}\text { Const } \\
\text { Material }\end{array}$ & Mzone & $\begin{array}{l}\text { WCC } \\
\text { Classn }\end{array}$ \\
\hline Abel Smith St & 32 & 59 & 235,000 & 215,000 & 75 & 2 & CC & 2 & C \\
Abel Smith St & 39 & 39 & 225,000 & 135,000 & 75 & 6 & CI & 2 & \\
Abel Smith St & 13 & 13 & 170,000 & 167,000 & 82 & 7 B & WI & 2 & \\
Abel Smith St & 17 & 35 & 71,000 & 43,500 & 80 & 5 & CI & 2 & C \\
Abel Smith St & 71 & 79 & 420,000 & 168,000 & 81 & 7 & CI & 2 & \\
Abel Smith St & 59 & 59 & 175,000 & 172,000 & 83 & X & XI & 2 & \\
Abel Smith St & 23 & 40 & 100,000 & 100,000 & 80 & P & WI & 2 & \\
Abel Smith St & 122 & 122 & 400,000 & 317,000 & 84 & 4 & CX & 2 & \\
Abel Smith St & 10 & 12 & 39,000 & 33,000 & 75 & X & XX & 2 & C \\
Abel Smith St & 37 & 74 & 220,000 & 85,000 & 70 & 7 A & CI & 2 & C \\
Abel Smith St & 78 & 111 & 278,000 & 277,000 & 80 & X & XX & 2 & B \\
Abel Smith St & 13 & 21 & 62,500 & 59,000 & 84 & 0 & WI & 2 & \\
Abel Smith St & 10 & 19 & 48,500 & 44,000 & 84 & 9 & WI & 2 & \\
Abel Smith St & 8 & 15 & 51,500 & 49,000 & 84 & 9 & WI & 2 & \\
Abel Smith St & 44 & 162 & 230,000 & 215,000 & 20 & X & BX & 2 & \\
Abel Smith St & 10 & 26 & 255,000 & 242,000 & 84 & X & XX & 2 & \\
Abel Smith St & 23 & 33 & 75,000 & 52,500 & 23 & X & XX & 2 & \\
Abel Smith St & 12 & 23 & 65,000 & 62,000 & 84 & 9 & WI & 2 & \\
Abel Smith St & 22 & 49 & 165,000 & 50,000 & 84 & $7 B$ & CI & 2 & C \\
\hline
\end{tabular}

Fig. 5.

Sample Computer Listing 
For example, a moderate to severely damaged older building would probably be demolished and rebuilt to current standards. It is also conceivable that the cost of restoring moderately to lightly damaged buildings to their pre-earthquake state without "betterment" (2) could easily exceed the indemnity value of the building. Consequently the estimates of damage computed in this study are likely to be low.

\subsubsection{Building Contents}

It is appreciated that, especially for an older building, the value of its contents could be of the same order as the market value of the building. The study group was unable to find significant published information on the relationship between damage to contents and modified Mercalli intensity.

Munich $\operatorname{Re}(13)$ suggests that there is a direct relationship between the loss estimate of a building and the loss of building contents as shown in Table 1 . However, other studies have taken a much coarser estimate of contents loss. In the absence of data from actual earthquakes, the study group obtained opinions of expected contents loss from two leading insurance companies and a leading loss adjuster. Based on these opinions, it was decided to use an estimate of contents loss in the case of housing equal to onethird of the housing loss. In the case of other buildings, 60 percent of building damage was used as an estimate of contents loss. This was based on further consideration (14) of data used in reference (3).

\subsection{Computation of Damage Costs \\ 3.5.1 Valuation Department Data}

The housing and other buildings data used in this study was obtained from Valuation Department information using two different methods.

For housing, a list of the local authorities within the area affected by earthquake intensity of MM VII and greater was compiled to cover all the four events. For the cities, boroughs and counties the total improved value of all the residential dwellings was obtained using valuation Department statistics. The latitudes and longitudes of the local authority centres were used to coordinate their positions and this information was stored on the computer dataset along with the associated improved values and a factor for updating these values to March 1983. Coordinate sets defining all the elliptical isoseismals for the four events (Figure 1) were compared with locations of housing groups in turn and the housing data records thus associated with appropriate MM intensities. The expected housing loss for each seismic event was then calculated using the MDR value for the respective MM intensities.

In the case of buildings other than houses, computer tape listings for the central business districts (CBD) were obtained from the Valuation Department for Christchurch, Nelson, Wellington/Hutt, Wanganui, Palmerston North, Hastings and Napier cities.

The above cities were used as models for other cities within the earthquake affected area for which no computer tape listings were obtained. For example, New Plymouth city was considered to have a similar distribution of building types as Wanganui city and adjustment to building loss was made to take account of the variation in total building value between the two cities. The additional buildings outside the CBD of a city were assumed to suffer the same average loss per building as those in the CBD. The total building value for each city was obtained from Valuation Department statistics.

Also obtained was the total value of non-housing buildings in towns of borough status. The majority of the buildings in these boroughs were assumed to be of older construction than typically occurs in the larger cities where redevelopment of the urban areas has occurred on a more frequent basis. The ratio of:

$$
\frac{\text { total building loss }}{\text { total building value }}
$$

as determined for Wanganui city was used to represent the proportion of building loss expected in these smaller urban centres for the respective intensity of ground shaking determined in any of the four scenario events.

Figure 5 shows the form of central building data used for the major urban areas. The record for each building contains mainly data obtained from Valuation Department land use data tapes: the street number, street name, site cover, floor area, capital value, land value, use, age and construction material. For the Wellington/Hutt metropolitan area, microzone data and, where known, the Wellington City Council building classification has been added. This information was used to determine the structural material and age of construction for each building.

\subsubsection{Computation}

The isoseismals for the four scenario events (Figure 1) indicate the various MM intensities affecting any particular urban centre.

The MDR value for the appropriate MM intensity was selected and a computer program was used to sort out building construction, microzone area and age category before computing the expected loss for each building. The loss was calculated as the product of MDR and the difference between capital value and land value for each building where the value was adjusted to March 1983. The values were summed to give a total expected building loss for each urban area, and finally for each 
event.

Government-owned buildings are not a charge on the Earthquake and War Damage Commission and so were separated from the computer listings.

\subsection{Sources of Error}

The principal source of doubt in the results of the study were considered to be the error in the mean damage ratio versus Mercalli intensity relationships. This was taken into account in the range of building losses calculated which allowed for \pm one standard deviation in the estimation of these factors. Other sources of error which contributed to the uncertainty of the final result included:

- assessment of distribution of earthquake intensities

- the limited number of building classes used in the study

- assessment of market values

- indemnity values (in this study assumed equal to market value)

- assessment of damage to contents.

These sources are difficult to quantify and no estimation has been made of the error resulting from them.

\section{RESULTS OF STUDY}

The results of building plus contents loss are given in Table 2 as relative values within the affected areas indicated in Figure 1. The range of loss shown is plus or minus one standard deviation, that is, there is a probability of approximately two-thirds that the actual loss lies within the listed range. The following observations can be made from consideration of Table 2:

- The highest percentage damage of the four scenario events, which occurs in event 3 (Figure 1), results in the highest relative value of damage. This event subjects buildings from Tauranga in the north to Westport in the south to intensities of MM VII or greater. The epicentre of the event is in an area where the building concentration is greatest.

- In the scenario areas the total value of housing was always greater than the total building value. However, the housing loss was typically around one-third of the value of the building loss.

\section{DISCUSSION}

5.1 The methodology provides a means by which a range of loss values can be calculated for a given earthquake. It is a refinement of methods used by previous researchers.

5.2 The study did not take into account the following:
- costs due to inflated rates for repair which may apply after a major disaster

- damage to buried building services

- likely cost of improvements in excess of basic repair costs

- indirect costs to the community such as loss of productivity.

5.3 Until such time as another major earthquake causes damage to a New Zealand urban centre, damage ratios will need to be obtained from overseas studies. This is expected to cause significant errors where construction standards vary greatly with those applying in New Zealand.

5.4 The lack of data on the damage ratios of buildings of modern construction and building contents in general, presented a problem for the study group and would affect the reliability of the loss study.

\section{ACKNOWLEDGEMENTS}

The authors gratefully acknowledge the permission of the Earthquake and War Damage Commission and the Commissioner of Works to publish this paper. The members of the study group were $D$ Hutchison, D J Dowrick, A K Perry, D J Darwin, C W Mouat and G R Birss.

\section{REFERENCES}

(1) Darwin D J, "Earthquake Hazard Reduction in Wellington". Department of Civil Engineering, University of Canterbury. Report No 80/1 - March 1980.

(2) Dowrick D J, "An Earthquake Catastrophe Damage Assessment Model with Particular Reference to Central New Zealand". Proc Third South Pacific Regional Conference on Earthquake Engineering, May 1979 .

(3) Smith $W \quad D$ and Berryman $K \quad R$, "Revised Estimates of Seismic Hazard in New Zealand". Bulletin New Zealand National Society for Earthquake Engineering. Vol 16, No 4, December 1983.

(4) Smith W D, "Spatial Distribution of Felt Intensities of New Zealand Earthquakes". New Zealand Journal Geology and Geophysics. Vol 21, No 3, 1978.

(5) "Microzoning for Earthquake Effects in Wellington". DSIR Bulletin 213, 1974.

(6) Berryman K R, A personal communication.

(7) Sherburd J E, "The settlement of Insurance Claims Following a Large Earthquake". Large Earthquakes in New Zealand. Royal Society New Zealand. Miscellaneous, Series 5, 1981.

(8) Whitman $R \mathrm{~V}$, "Damage Probability Matrices for Prototype Buildings". Seismic Design Decision Analysis. Report No 8. Massachusetts Institute of Technology, 1973 . 
(9) Cooney $\mathrm{R} C$ and Fowkes A H R, "New Zealand Houses in Earthquakes - What will Happen?" Large Earthquakes in New Zealand. Royal Society New Zealand. Miscellaneous. Series 5, 1981.

(10) MP 12: 1965, Commentary on Chapter 8 of NZSS 1900 .

(11) Whitman $R \quad V$, Hong $S T$ and Reed $J$ W, "Optimum Seismic Protection and Building Damage Statistics". Seismic Design Decision Analysis. Report No 7. Massachusetts Institute of Technology, 1973.

(12) Steinbrugge $\mathrm{K} \quad \mathrm{V}$, "Earthquake Disaster Response Planning: An Engineering Overview". Bulletin New Zealand National Society for Earthquake Engineering, Vol 8, No 2, June 1975 .

(13) Munich Re, "Handbook to World Map of Natural Hazards". Munich Reinsurance Company, 1978.

(14) Dowrick D J. A personal communication.

TABLE 1

\begin{tabular}{|c|c|c|c|c|c|c|c|c|}
\hline MUNICH & $\mathrm{RE}$ & EST & IATE & $\mathrm{F}$ CON'T & JTS & SS & & \\
\hline MM Intensity & & VI & VII & VIII & IX & $\mathrm{X}$ & $X I$ & XII \\
\hline $\begin{array}{l}\text { Proportion of } \\
\text { Building Loss }\end{array}$ & & $1 / 5$ & $1 / 4$ & $1 / 3$ & $1 / 2$ & $2 / 3$ & $4 / 5$ & $9 / 10$ \\
\hline
\end{tabular}

TABLE 2

\begin{tabular}{|c|c|c|c|c|}
\hline \multicolumn{5}{|c|}{$\begin{array}{c}\text { RELATIVE VALUES OF ESTIMATED LOSS FOR } \\
\text { BUILDINGS AND CONTENTS }\end{array}$} \\
\hline \multirow{2}{*}{$\begin{array}{l}\text { Category of Loss } \\
\qquad \text { Event } \longrightarrow\end{array}$} & \multicolumn{4}{|c|}{ Range } \\
\hline & $\begin{array}{l}{ }^{1} \\
\text { MMIX in } \\
\text { Wellington }\end{array}$ & $\begin{array}{l}2 \\
\text { MMIX in } \\
\text { Wellington }\end{array}$ & $\begin{array}{l}{ }^{3} \\
\text { MMX in } \\
\text { Wellington }\end{array}$ & $\begin{array}{l}4 \\
\text { MMX in } \\
\text { Wellington }\end{array}$ \\
\hline Houses & 1.4 to 2.1 & 1.0 to 2.5 & 1.9 to 2.9 & 1.6 to 2.4 \\
\hline Other Buildings & 3.1 to 7.0 & 2.2 to 4.9 & 5.6 to 10.1 & 4.7 to 8.0 \\
\hline Total & 4.5 to 9.1 & 3.2 to 6.4 & 7.5 to 13.0 & 6.3 to 10.4 \\
\hline
\end{tabular}

